\title{
Parameterization of solar radiation from model and observations
}

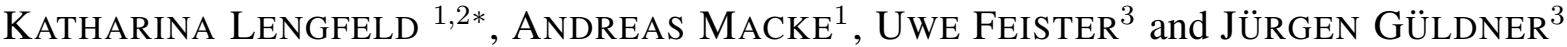 \\ ${ }^{1}$ IFM-GEOMAR Leibniz Institute for Marine Science, Kiel, Germany \\ ${ }^{2}$ Meteologisches Institut, University of Hamburg, Germany \\ ${ }^{3}$ Deutscher Wetterdienst, Lindenberg, Germany
}

(Manuscript received September 7, 2009; in revised form December 10, 2009; accepted December 10, 2009)

\begin{abstract}
The influence of the external and internal structure of clouds on the incoming solar radiation cannot yet be included in parameterizations used in numerical models. Based on numerical simulations, SCHEWSKI and MACKE (2003) (Schewski-parameterization) have shown that a robust link exists between the domain averaged cloud and the domain averaged solar broadband radiation fluxes, despite the $3 \mathrm{~d}$ nature of the cloud fields involved. The present work revisits this approach with observed cloud (cloud cover and liquid water path) and radiation (downwelling shortwave radiative flux) properties obtained from the Richard Assmann Observatory (RAO) of the German Weather Service in Lindenberg. Applying the original (model based) cloud-radiation parameterization by SCHEWSKI and MACKE (2001) to observed domain averaged cloud fields yields an overall good correlation between observed and parameterized downwelling solar radiation fluxes. However, the parameterized fluxes strongly underestimate the observations. The Schewski parameterization has been modified by removing the bias and re-adjusting the parameterization coefficients to match the observed cloud and radiation correlation. Furthermore, the empirical parameterization by ZILLMAN (1972) has been implemented for describing the clear conditions. Applying the new parameterization to an independent data set provides significant improvements. However, the accuracy remains in the order of previously used one- or two-parameter empirical cloud-radiation parameterizations. We conclude that cloud cover and liquid water path, i.e. those data that are available from large scale climate models, cannot be regarded as sufficient to describe the cloud radiative effect at the surface.
\end{abstract}

\section{Zusammenfassung}

Der Einfluss der internen Struktur von Wolken auf die einfallende solare Strahlung kann bisher nicht in Parametrisierungen erfasst werden, die in numerischen Modellen verwendet werden. Basierend auf numerischen Simulationen haben SCHEWSKI and MACKE (2003) (Schewski-Parameterisierung) gezeigt, dass trotz der Vernachlässigung der dreidimensionalen Struktur der Wolkenfelder eine starke Verbindung zwischen den gebietsgemittelten Wolken und den gebietsgemittelten solaren breitbandigen Strahlungsflüssen besteht. Diese Arbeit verfolgt diesen Ansatz mit beobachteten Wolken- (Bedeckungsgrad und Flüssigwasserpfad) und Strahlungseigenschaften (nach unten gerichteter kurzwelliger Strahlungsfluss), die vom Richard-AßmannObservatorium (RAO) des Deutschen Wetterdienstes Lindenberg gemessen wurden. Die Anwendung der ursprünglichen (auf Modellen basierenden) Wolken-Strahlungsparametrisierung von SCHEWSKI and MACKE (2001) auf gebietsgemittelte Wolkenfelder liefert insgesamt eine gute Korrelation zwischen beobachtetem und parametrisiertem nach unten gerichtetem Strahlungsfluss. Allerdings unterschätzen die parametrisierten Flüsse die Beobachtungen deutlich. Die Schewski-Parameterisierung wurde modifiziert, indem der systematische Fehler beseitigt wurde und die Koeffizienten der Parametrisierung an die Beobachtungen angepasst wurden, so dass die Korrelationen zwischen Beobachtung und Parametrisierung möglichst hoch ist. Darüber hinaus wurde die empirische Parametrisierung von ZILLMAN (1972) eingesetzt um den wolkenfreien Fall zu beschreiben. Die Anwendung der neuen Parametrisierungen auf einen unabhängigen Datensatz brachte signifikanten Verbesserungen. Die Genauigkeit bleibt in der Größenordnung von früher benutzten empirischen Parametrisierungen mit ein oder zwei Parametern. Wir folgern daraus, dass Bedeckungsgrad und Flüssigwasserpfad, d.h. die Daten, die in großskaligen Klimamodellen zur Verfügung stehen, nicht ausreichen um den Wolken-Strahlungseffekt am Boden zu beschreiben.

\section{Introduction}

On the way through the atmosphere the solar radiation field is influenced mainly by clouds, i.e. by their complex three-dimensional (3d) external and internal structure. The amount of transmitted radiation that reaches

\footnotetext{
${ }^{*}$ Corresponding author: Katharina Lengfeld, Meteorological Institute, University of Hamburg, Bundesstr. 55, 20146 Hamburg, Germany, e-mail: katharina.lengfeld@zmaw.de
}

the surface is of special interest as it is responsible for surface heating which in turn mostly drives the dynamics of our planet. It is obvious that practical parameterizations of the transmitted solar radiation cannot account for the full $3 \mathrm{~d}$ structure of the cloudy atmosphere. The same is true for radiative transfer modelling in large scale, i.e. in non cloud-resolving atmospheric circulation models. NiEMELÄ et al. (2001), DOBSON and SMITH (1988) and KIZU (1998) compared several parameterizations for shortwave incoming radiation with hourly or 
daily averaged measurements. They show systematic errors especially for high cloud cover.

In the past several attempts have been made to calculate that part of the shortwave radiation that reaches the surface without taking the internal structure of the clouds into account. Generally the incoming solar radiation flux density $Q_{S W}$ in $\left[\mathrm{W} / \mathrm{m}^{2}\right]$ reaching the surface is described by the solar constant $S_{0}$, the sun zenith angle $\theta$, and a transmission factor $T_{F}$, which in turn depends on the composition of the atmosphere (LIOU, 1980).

$$
Q_{S W}=S_{0} \cdot \cos \theta \cdot T_{F}
$$

One of the first formulas for the transmission factor was developed by LUMB (1964). He assumed a linear relation between incoming solar radiation and the sun zenith angle:

$$
T_{F}=a_{i}+b_{i} \cos \theta, \quad \text { with } i=1, \ldots, 9 .
$$

We subdivided the clouds into categories based on cloud type and cloud cover and fitted the coefficients $a$ and $b$ for each category based on observations. Later LIND et al. (1984) expanded these categories.

DOBSON and SMITH (1988) suggested a nonlinear relationship between the transmission and the solar zenith angle depending on cloud cover and the presence of snowfall or fog.

$$
\begin{gathered}
T_{F}= \\
F \cdot \exp \left(-D_{0} / \cos \theta\right) . \\
\left(N\left[\exp \left(-D_{i} / \cos \theta\right)+E_{i}\right]+(1-N)\right),
\end{gathered}
$$

where $\mathrm{F}$ is the part of the shortwave radiation that is absorbed by gases under clear sky conditions, $D_{0}$ the optical thickness of the cloud free atmosphere, $D_{i}$ the optical thickness for direct radiation, $E_{i}$ the transmission factor of clouds for diffuse insolation and $\mathrm{N}$ the cloud cover.

All parameterizations mentioned above require simultaneous surface radiation measurements and sky observations. The latter are usually performed by a human observer and are subject to misinterpretation and - more importantly - are not reproducible. Therefore, ZILLMAN (1972) developed a parameterization for the incoming solar radiation that only depends on physically based observations, which are the sun zenith angle, the water vapour pressure, and the cloud cover.

A completely different approach to develop a parameterization for the downwelling shortwave radiation at the surface is to use most realistic $3 \mathrm{~d}$ radiative transfer calculations for state-of-the-art $3 \mathrm{~d}$ model cloud fields. This strategy is pursued by SCHEWSKI and MACKE (2003). They correlated the domain averaged radiation fluxes at the model boundaries with the domain averaged cloud properties and found a surprisingly high correlation despite the strong variability of the cloud macro- and microphysical properties. For application in climate models they developed a parameterization of the solar transmittance as a function of cloud cover and liquid water path. These two parameters produced the highest correlation, and they are also available from observations and from large scale non-cloud resolving models. Note that by means the largest influence was found for cloud cover for a given solar elevation. Thus, the disussion further below is focused on cloud cover variability rather than on variations in the amount of condensed water.

The purpose of this study is to apply the model-based Schewski parameterization to observed cloud properties, to test its quality, and to provide an improved parameterization based on observed cloud cover and cloud liquid water path as described in Section 2. Section 3 provides a short introduction into the different radiation parameterizations used in this study. The application of the parameterization to observed cloud properties and a comparison to the observed downwelling surface radiation is given in Section 4. The parameterization coefficients will be adjusted to the measured pairs of cloud and radiation properties, and a validation with another independent dataset will be performed. Section 5 presents the conclusions.

\section{Data}

The dataset used in this study is derived from the Richard Assmann Observatory (RAO) in Lindenberg. The RAO is part of the German Weather Service (DWD).

The cloud cover was calculated from pictures of a Whole Sky Imager. The DAY VIS/NIR Whole Sky Imager (WSI) designed and built at the University of California San Diego (SHIELDS et al., 1998) has been in operation at the German Weather Service since 2000 (FEISTER and SHIELDS, 2005). Images of the upper hemisphere $\left(180^{\circ}\right.$ viewing angle) are acquired every 10 or 5 minutes in up to 7 different spectral ranges in the visible (VIS) and near infrared (NIR) region. Cloud fraction of optically thin and opaque clouds for the upper hemisphere and for selected regions of interest are derived by a cloud decision algorithm from images in two different spectral regions. In this study, images aquired in the blue (434-480 $\mathrm{nm}$ ) and near infrared (845-942 $\mathrm{nm}$ ) region were used for cloud cover post-processing. Time distances between two images of one sequence are less than $30 \mathrm{~s}$ for most of the daylight time, but can be longer for very long exposure times with thick clouds and large solar zenith angles, i.e. at low brightness conditions.

Comparisons between cloud cover derived from WSI data over a period of two years and conventional cloud observations at the sites Potsdam and Lindenberg had shown corresponding results within \pm 2 Okta in $80 \%$ of the cases for sun zenith angles of less than $80^{\circ}$ (FEISTER and SHIELDS, 2005). A comparison between WSI cloud decision and ceilometer LD-40 cloud-base decision over a period of 1.5 years showed correspondence in zenith sky cloud detection in 69 to $73 \%$ of the cases. One of the probable causes of no-coincidence cases between WSI and ceilometer was the ceilometer's 
low sensitivity and thus its reduced capability in detecting high-level (optically thin) clouds.

A close correspondence between cloud cover derived from WSI data and another instrument was found from a data analysis of a four-months comparison campaign between the WSI instrument and an infrared sky scanner called Nubiscope. Correspondence in cloud detection capabilities occured in $95 \%$ of the cases considered. Differences between cloud fractions from both instruments were less than \pm 2 Okta in $75 \%$ of all cases (FEISTER et al., submitted).

The cloud liquid water path (LWP) at the Meteorological Observatory Lindenberg results from measurements of the microwave profiler TP/WVP 3000 made by Radiometrics (SOLHEIM et al., 1998). The radiometer is in use since 1998 and it is able to provide the vertical profiles of the temperature, water vapour and liquid water content up to $10 \mathrm{~km}$ height as well as the LWP (GÜLDNER and SPÄNKUCH, 2001; WARE et al., 2003). The measurements are taken in a temporal resolution of 1 minute and are archived in the database Lindenberger Säule as 10 minute means.

The radiometer measures the radiance at 12 frequencies in the range of $22-30 \mathrm{GHz}$ and $51-59 \mathrm{GHz}$, where the microwave emission spectrum is dominated by water vapour, liquid water, and molecular oxygen. The observations represent a field of view ranging from $6^{\circ}$ in the oxygen band to about $2.5^{\circ}$ along the water vapour line. The vertical profiles and the LWP can be derived with the help of a neural net (NN) using the measured brightness temperatures of the microwave profiler and the associated meteorological ground observations. For compiling the $\mathrm{NN}$ a representative training data set of radiosonde ascents was used. For this dataset the theoretical radiances were derived using a radiative transfer model. The computation of the NN for the liquid water content and the LWP was made by assuming that, after a certain threshold of the relative humidity $(95 \%)$ is trespassed, liquid water occurs. Furthermore it is assumed that in between the defined borders of the cloud a saturated adiabatic ascent of the air parcel occurs.

The following analyses use the LWP values derived from the NN. Analyses of the error structure of the results were described in GÜLDNER and LEPS (2005). The mean accuracy of LWP is expected to be in the order of $0.03 \mathrm{~kg} / \mathrm{m}^{2}$ or about $20 \%$ (LÖHNERT and CREWELL, 2003).

The global shortwave radiation is directly measured by a Kipp \& Zonen CM22 pyranometer. The pyranometer is ventilated and slightly heated. The Lindenberg site is part of the Baseline Surface Radiation Network (BSRN) and therefore provides high quality data. The accuracy of the CM22 pyranometer is in the order of $2 \%$ $\left(5 \mathrm{~W} / \mathrm{m}^{2}\right)$ (MCARTHUR, 2005). The calibration of the pyranometers is based on the Sun Disk Method (WMO, 2008) using absolute radiometers for direct irradiance as a reference that are regularly calibrated at the World Radiation Center in Davos (Switzerland).

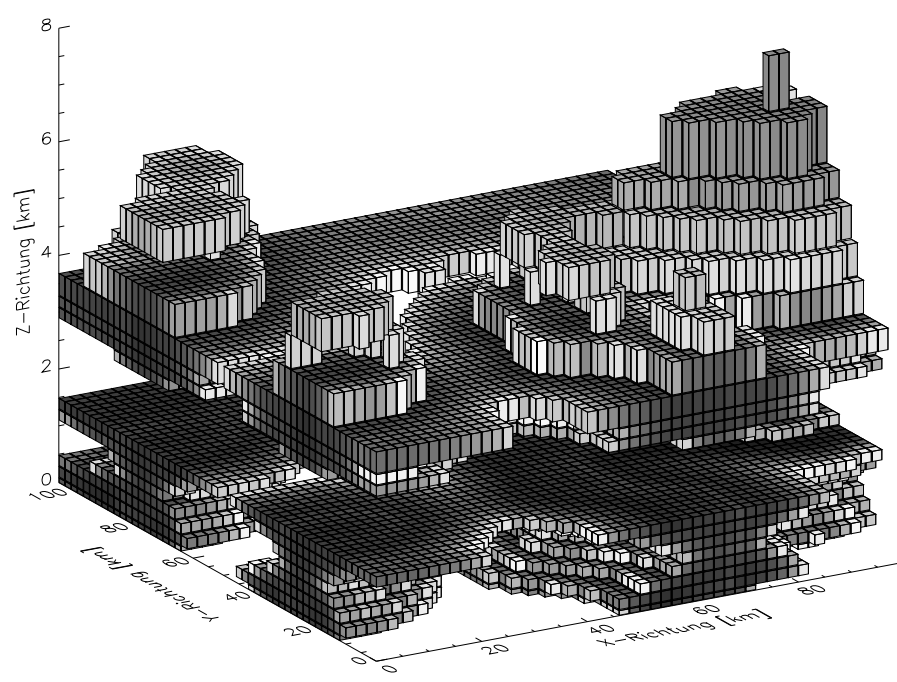

Figure 1: 3 dimensional cloud from GESIMA. Darker colours represent higher volume extinction coefficients.

Besides these data, the temperature at the surface and the relative humidity are used.

\section{Parametrizations}

The parameterization for the incoming shortwave radiation used in this study is based on model calculations. SCHEWSKI and MACKE (2003) applied the 3d mesoscale model GESIMA to compute 3d cloud fields with microphysical properties for liquid water, rain, ice and snow. GESIMA was run with a horizontal resolution of $2 \mathrm{~km}$ and 25 layers between $100 \mathrm{~m}$ and $10 \mathrm{~km}$ with a vertical resolution of $100 \mathrm{~m}$ near the ground and 1000 $\mathrm{m}$ in upper layers. The modelling area is $104 \times 104 \mathrm{~km}$ wide. For a more detailed description of the model see also EPPEL et al. (1992) and EPPEL et al. (1995).

For modelling the microphysical processes the cloud module of LEVKOV et al. (1992) is used. Levkov distinguished between water vapour, cloud liquid water, rain, ice crystals and snow, so that ice, water and mixed phase clouds are possible in each model grid box. As initial conditions 152 radiosonde ascents from a global dataset were used for creating 756 independent cloud fields. An example of such a field is shown in Figure 1. Because of the relatively small model area only stratocumulusand cumulus-clouds can occur. That leads to a systematic error in situations with high and mid-level clouds. To minimize this error we excluded cases with non-zero cloud cover but zero liquid water path as it can occur in the presence of cirrus clouds. 
Table 1: Correlation between parameterized and modelled total transmission for one, two and three cloud properties for a sun zenith angle of $50^{\circ}$

\begin{tabular}{|c|c|c|c|}
\hline parameter & $\mathrm{N}$ & LWP, N & LWP, N, $T^{C T}$ \\
\hline corr & 0.789 & 0.895 & 0.929 \\
\hline
\end{tabular}

To construct the radiation parametrization the data from GESIMA were applied as input to the Monte-Carlo radiative transfer model GRIMALDI (SCHEIRER and MACKE, 2003). A detailed description of the MonteCarlo method can be found in MARCHUK et al. (1980). The physical cloud properties delivered by GESIMA had to be transformed into optical properties that can be used by GRIMALDI. Depending on the phase of the water and the particle effective radii as well as their distribution in each model box, the box averaged single scattering albedo and the scattering function is calculated as described in MACKE et al. (1999). The domain averaged reflected, absorbed and transmitted radiative fluxes are calculated for nine different sun zenith angles in $10^{\circ}$ steps between $0^{\circ}$ and $80^{\circ} .13$ spectral bands are used to cover the whole solar spectral range.

SCHEWSKI and MACKE (2003) applied the following formula for the transmission factor:

$$
T=a+\sum_{j=1}^{n} b_{j} \sqrt{C_{j}}+c_{j} C_{j}+d_{j} C_{j}^{2},
$$

where $C_{j}$ describes the cloud properties. The quadratic and the square root term were added because of the nonlinear relation between the cloud properties and the transmitted solar radiation. The number of cloud properties used for the parameterization between domain averaged cloud and radiation properties is limited to three. With an EOF analysis the best fitting properties were found. In Table 1 the correlation between parameterized and calculated solar transmission for a sun zenith angle of $50^{\circ}$ is shown. Figure 2 shows the correlation for every sun zenith angle for the three best fitting cloud properties; the cloud cover $\mathrm{N}$, the liquid water path LWP and the cloud top temperature $T^{C T}$. In the present study only the two best fitting cloud properties, the cloud cover and the liquid water path, are used, because the data have been available and the correlation of 0.895 appears satisfying. Therefore, only 7 parameterization coefficients had to be adjusted for every sun zenith angle in Eq. 3.1.

For clear-sky conditions a modification of the parameterization according to ZILLMAN (1972) is used in this study. It only depends on the sun zenith angle, the water vapour pressure $p_{w}$ and the cloud cover. The clear-sky transmission factor is calculated as follows:

$$
T_{0}=\frac{\cos \theta}{(\cos \theta+a) p_{w} 10^{-3}+b \cos \theta+c}
$$

The coefficients $a, b$ and $c$ were determined by KALISCH and MACKE (2008) based on measurements on several

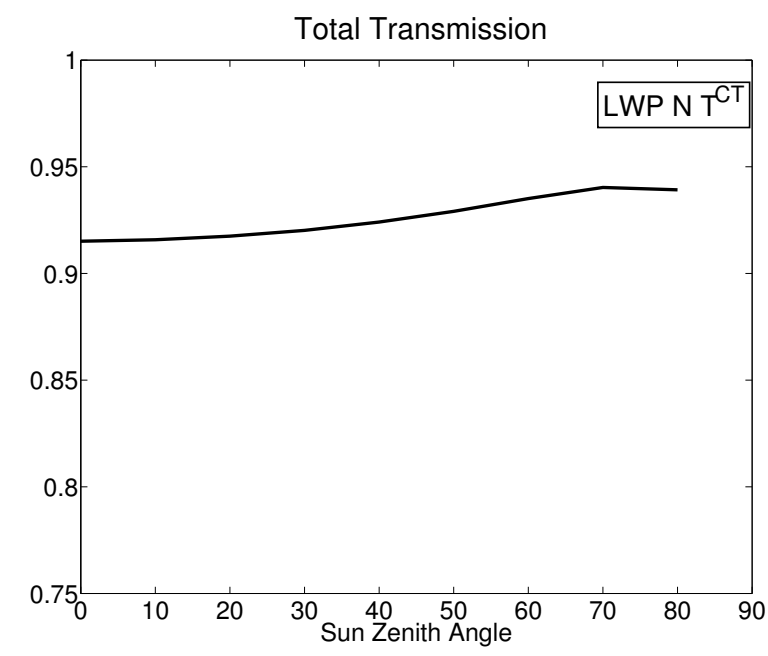

Figure 2: Correlation for the best three cloud parameters (cloud cover N, liquid water path LWP and cloud top temperature $T^{C T}$ ) as a function of the sun zenith angle

ship cruises across the Atlantic Ocean. The Zillman parameterization with these coefficients shows comparable results for clear sky conditions to other parameterizations (NIEMELÄ et al., 2001) although it was calculated for one minute means of the solar radiation instead of hourly means.

\section{Results and discussion}

First, the original purely model based parameterization by SCHEWSKI and MACKE (2003) was applied to the measured cloud cover and liquid water path from Lindenberg of the year 2007. Situations with non-zero cloud cover but zero liquid water path as it can occur in the presence of cirrus clouds have been taken out of our analysis (DUPONT et al., 2008). In Figure 3a a comparison between the measured and the parameterized transmitted radiation is shown. The colours denote cloud cover from 0 to 8 octa. The red line represents the points where measurements and calculations match. The original Schewski-parameterization (oSP) underestimates the measurements especially at large radiation values, i.e. for low cloud cover and/or high sun conditions. At small values, which are mostly associated with large cloud cover the observed radiation is slightly overestimated by the parameterization. Note that the scatter is much stronger at large to medium cloud cover values, whereas a general bias dominates for skies with fewer clouds. Obviously, the large variability of cloud realizations for the same cloud cover renders an accurate parameterization difficult. The bias at small cloud cover indicates a problem with the clear sky parameterization which will be addressed later. A brief statistical analysis is presented in Table 2. The mean difference $(\overline{\Delta Q})$ between the parameterization and the measurements is $-68.18 \mathrm{~W} / \mathrm{m}^{2}$. The standard deviation is $117.5 \mathrm{~W} / \mathrm{m}^{2}$. 

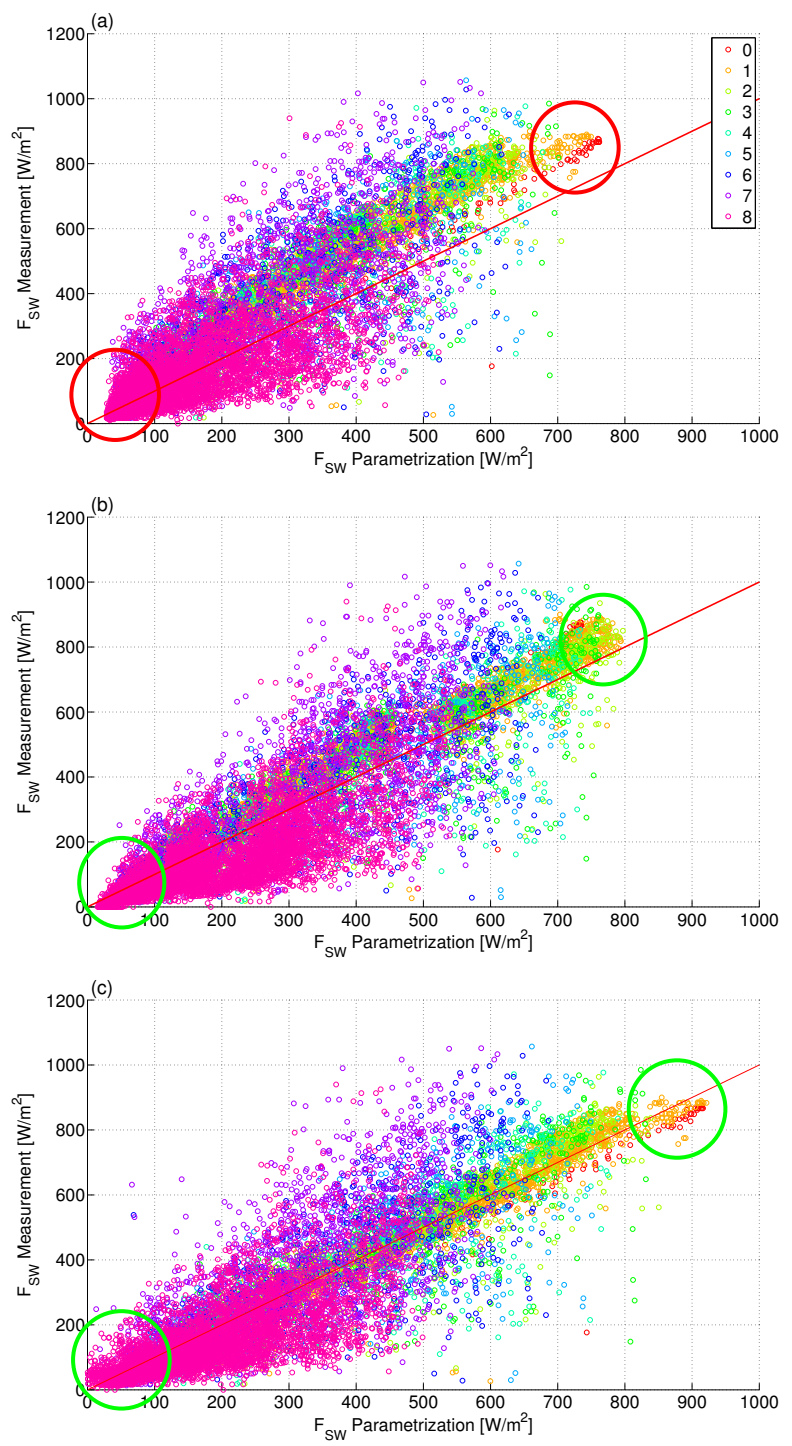

Figure 3: Comparison between measured and parameterized incoming radiation $\left[W / m^{2}\right]$ for the $o S P$ (a), the $m S P_{0}$ (b) and the $m S P Z_{0}$ (c). Different colours stand for cloud cover from 0 to 8 octa.

Table 2: Mean differences $(\overline{\Delta Q})$ between parameterization and measurement, the standard deviation $(\sigma)$ of the differences and the correlation (corr) between calculated and measured insolation

\begin{tabular}{|c|c|c|c|}
\hline & $\overline{\Delta Q}\left[W / m^{2}\right]$ & $\sigma\left[W / m^{2}\right]$ & corr \\
\hline \hline$o S P$ & -68.18 & 117.49 & 0.875 \\
\hline$m S P_{0}$ & 0 & 102.01 & 0.91 \\
\hline$m S P Z_{0}$ & 0 & 102.04 & 0.9 \\
\hline
\end{tabular}

The Spearman-rank-correlation is 0.875 . This value is similar though somewhat smaller than for the original model cloud versus model radiation correlation given in Table 1.

In a second step, the coefficients of the oSP have been adjusted to the observed pairs of cloud and radi- ation properties so that the average difference is 0 , the standard deviation is minimized, and the correlation coefficient is maximized. The new coefficients are listed in Table 3.

Figure $3 \mathrm{~b}$ illustrates the comparison between the measured transmitted solar radiation flux density and the results from the modified parameterization $\left(m S P_{0}\right)$. The $m S P_{0}$ agrees better with the measurements especially for very high and small radiation values, i.e. for mostly clear and mostly cloudy skies as indicated by the colours. The standard deviation is reduced to $102.01 \mathrm{~W} / \mathrm{m}^{2}$ which is $15 \mathrm{~W} / \mathrm{m}^{2}$ less than that for the oSP. The correlation is enhanced by 0.035 to 0.91 .

In a third step, the parameterization coefficient $a$ which describes the clear sky case is replaced by the more physically based parameterization according to Zillman, where the atmospheric humidity is taken into account. This new parameterization now is of the form:

$$
F=F_{\text {illman }_{\text {clear }}}+\left(\sum_{j=1}^{n} b_{j} \sqrt{C_{j}}+c_{j} C_{j}+d_{j} C_{j}^{2}\right) \cdot F_{T O A} .
$$

where $F_{Z_{\text {illman }} \text { clear }}$ is the Zillman parameterization for clear sky conditions. The coefficients $b_{j}, c_{j}$ and $d_{j}$ were adjusted again as described before. Figure $3 \mathrm{c}$ shows the comparison between the results from the Schewski parameterization with the Zillman parameterization for clear sky (denoted as $m S P Z_{0}$ ) and the measurements of the shortwave solar radiation. It appears similar to the middle panel only that the $m S P Z_{0}$ seems to reproduce the high values of radiation a little better than the $m S P_{0}$. As expected the $m S P Z_{0}$ better reproduces the clear or nearly clear cases. The standard deviation is $102.04 \mathrm{~W} / \mathrm{m}^{2}$ and, therefore, slightly higher than for the $m S P_{0}$. Also the correlation is slightly lower. It amounts to 0.9 . The two modified versions of the Schewski parameterization provide similar results. The magnitude of the standard deviation is similar to that shown in the study of KALISCH and MACKE (2008), who applied the original Zillman parameterization under all cloud conditions. Apparently, the additional information LWP does not substantially improve the overall accuracy of the parameterization.

In the following the performance of the different parameterizations is discussed in more detail for four days with different cloud scenarios. The first example is the $8^{\text {th }}$ of July 2007 with broken clouds shown in Figure 4a. The right panel shows the cloud cover in percent in red and the liquid water path (LWP) in $\mathrm{kg} / \mathrm{m}^{2}$ in blue. This is a day with a nearly continuously fast fluctuating cloudiness between $30 \%$ and $80 \%$. The LWP is relatively constant and lower than $0.1 \mathrm{~kg} / \mathrm{m}^{2}$. In the left panel the observed downwelling shortwave radiation at the surface is shown in black and the results of the parameterizations in different colours: the original Schewski parameterization in blue, the $m S P_{0}$ in red and the $m S P Z_{0}$ in green. The differences between measured and parameterized radiation fluxes are depicted 
Table 3: Coefficients for the Schewski parameterization fitted to the dataset of Lindenberg 2007

\begin{tabular}{|c|c|c|c|c|c|c|c|}
\hline$\theta$ & $a$ & $b_{N}$ & $b_{L W P}$ & $c_{N}$ & $c_{L W P}$ & $d_{N}$ & $d_{L W P}$ \\
\hline \hline $30^{\circ}$ & 0.6269 & -01112 & 0.5011 & 0.2691 & -2.5147 & -0.3587 & 2.997 \\
\hline $40^{\circ}$ & 0.6276 & -0.2188 & 0.5248 & -0.1623 & -2.1282 & -0.274 & 2.0065 \\
\hline $50^{\circ}$ & 0.5936 & 0.2638 & 0.579 & -0.2141 & -2.0562 & -0.2799 & 1.938 \\
\hline $60^{\circ}$ & 0.545 & -0.0774 & 0.5791 & 0.2554 & -1.9732 & -0.336 & 1.617 \\
\hline $70^{\circ}$ & 0.5191 & -0.0499 & 0.6514 & 0.1482 & -2.212 & -0.324 & 2.1218 \\
\hline $80^{\circ}$ & 0.4197 & 0.0295 & 0.4947 & -0.0003 & -1.7542 & -0.1843 & 1.3211 \\
\hline
\end{tabular}
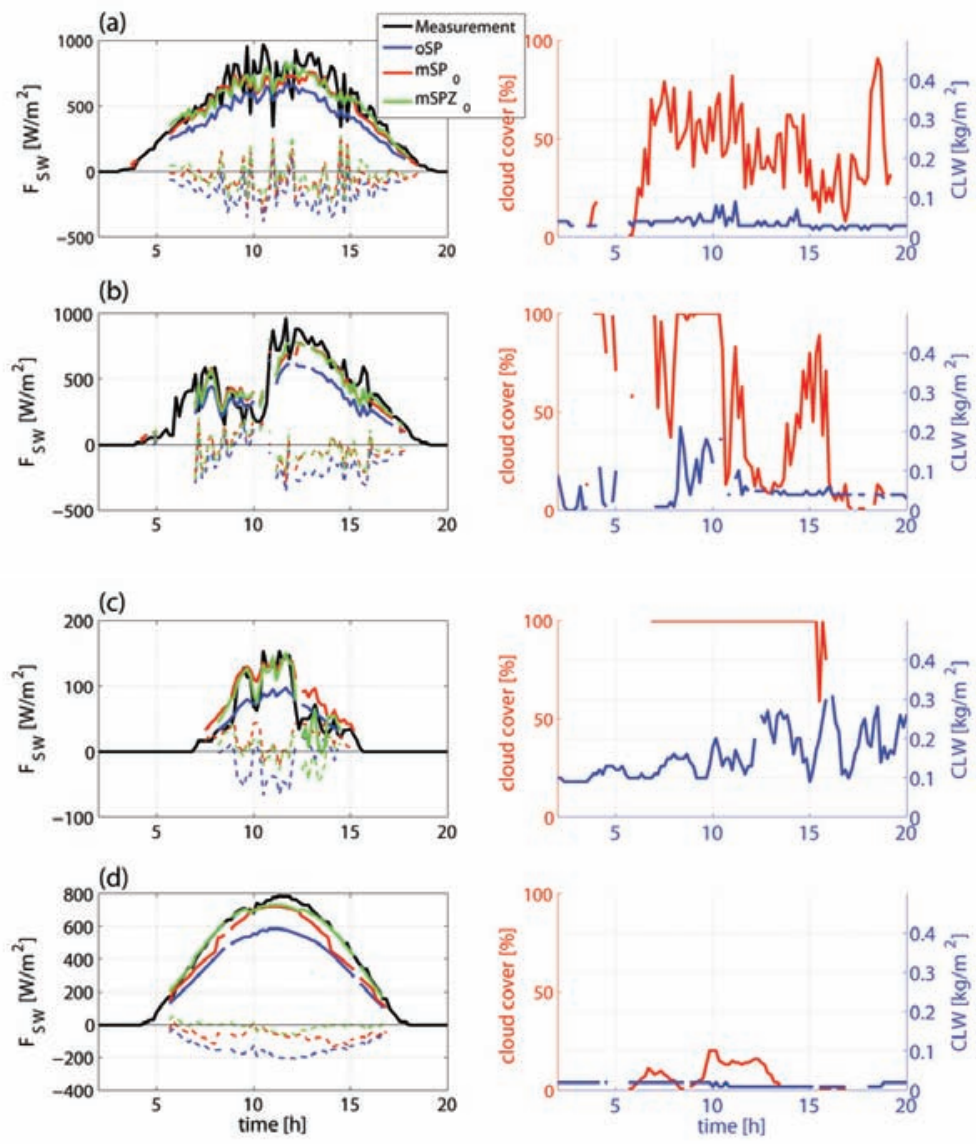

Figure 4: $8^{\text {th }}$ (a), $27^{\text {th }}$ (b) of July, $5^{\text {th }}$ of February (c) and $16^{\text {th }}$ of April (d) 2007. The left panels show the measurements in black, the parameterizations in colour and their differences (dashed lines), the right panels show the cloud cover in red and the LWP in blue.

by the coloured dashed lines. The oSP underestimates the measurements during the entire day. The two other parameterizations fit quite well to the measurements although both are not able to reproduce the local maxima and minima.

In Table 4 the results of the statistical analysis for the four example-days are given. For the $8^{\text {th }}$ of July the two modified SPs yield better results than the original SP. The mean difference and the standard deviation are lower and the correlation is higher than for the oSP, except the correlation for the $m S P Z_{0}$. The mean difference between observed and parameterized fluxes is smaller for the $m S P Z_{0}$ by $34.28 \mathrm{~W} / \mathrm{m}^{2}$. On the other hand the standard deviation is lower and the correlation is better.

The $27^{\text {th }}$ of July is a day with slow fluctuating cloudiness (figure 4b). The cloud cover varies between 20 $\%$ and $100 \%$. In the evening the sky is clearing up. The LWP varies between $0 \mathrm{~kg} / \mathrm{m}^{2}$ and $0.2 \mathrm{~kg} / \mathrm{m}^{2}$ until local noon. After noon the LWP is nearly constant at $0.04 \mathrm{~kg} / \mathrm{m}^{2}$. In the left panel of Figure $4 \mathrm{~b}$ the original Schewski parameterization (blue) underestimates the measurements again almost along the whole day except for the overcast time period between 8 and 10 am where all three parameterizations overestimate the observed radiation. For the rest of the day the two modified versions match the measured radiation quite well. The averaged difference is reduced from 
Table 4: Statistical analysis for the days $8^{\text {th }}$ and $27^{\text {th }}$ of July, $5^{\text {th }}$ of February and $16^{\text {th }}$ of April 2007

\begin{tabular}{|c|c|c|c|c|}
\hline Date & Parametr. & $\overline{\Delta Q}$ & $\sigma$ & corr \\
\hline \hline \multirow{3}{*}{ July $8^{\text {th }}$} & $o S P$ & -139.51 & 113.22 & 0.85 \\
\cline { 2 - 5 } & $m S P_{0}$ & -47.81 & 107.07 & 0.853 \\
\cline { 2 - 5 } & $m S P Z_{0}$ & -34.28 & 111.19 & 0.84 \\
\hline \hline \multirow{3}{*}{ July $27^{\text {th }}$} & $o S P$ & -103.37 & 126.43 & 0.893 \\
\cline { 2 - 5 } & $m S P_{0}$ & -28.7 & 110.05 & 0.9 \\
\cline { 2 - 5 } & $m S P Z_{0}$ & -25.85 & 112.82 & 0.853 \\
\hline \hline \multirow{3}{*}{ Feb $5^{\text {th }}$} & $o S P$ & -14.41 & 27.66 & 0.882 \\
\cline { 2 - 5 } & $m S P_{0}$ & 19.59 & 16.99 & 0.89 \\
\cline { 2 - 5 } & $m S P Z_{0}$ & -1.21 & 21.2 & 0.784 \\
\hline \hline \multirow{3}{*}{ Apr $16^{\text {th }}$} & $o S P$ & -143.81 & 46.0 & 0.968 \\
\cline { 2 - 5 } & $m S P_{0}$ & -64.77 & 32.91 & 0.946 \\
\cline { 2 - 5 } & $m S P Z_{0}$ & -11.57 & 24.77 & 0.967 \\
\hline
\end{tabular}

$-103.37 \mathrm{~W} / \mathrm{m}^{2}$ to $-28.7 \mathrm{~W} / \mathrm{m}^{2}$ for the $m S P_{0}$ respectively $-25.85 \mathrm{~W} / \mathrm{m}^{2}$ for the $m S P Z_{0}$. The standard deviation is also reduced to $110.05 \mathrm{~W} / \mathrm{m}^{2}$ for the $m S P_{0}$. This version also shows the best correlation of 0.9 .

The $5^{\text {th }}$ of February in Figure $4 \mathrm{c}$ is completely overcast. The LWP varies between $0.1 \mathrm{~kg} / \mathrm{m}^{2}$ and $0.2 \mathrm{~kg} / \mathrm{m}^{2}$ in the morning and between $0.1 \mathrm{~kg} / \mathrm{m}^{2}$ and $0.3 \mathrm{~kg} / \mathrm{m}^{2}$ in the afternoon. Again, the original Schewski parameterization underestimates the measurements and does not reproduce the maxima and minima of the measured fluxes (black curve). The $m S P_{0}$ matches the measurements well until noontime and overestimates them afterwards. The statistical parameters are best for the $m S P_{0}$ except for the mean difference. The standard deviation is lower by $16.99 \mathrm{~W} / \mathrm{m}^{2}$, the correlation is with 0.89 slightly higher than for the oSP. Only the mean difference is lowest for the $m S P Z_{0}$. It amounts only to $-1.21 \mathrm{~W} / \mathrm{m}^{2}$. Altogether the $m S P_{0}$ fits best for overcast sky conditions.

On the $16^{\text {th }}$ April there were only few clouds with low LWP. Again, the oSP underestimates the measurements on average by $143.81 \mathrm{~W} / \mathrm{m}^{2}$, but it shows the highest correlation. The large difference between the measurements and the parameterizations can be explained by the fact that no clear sky cases were taken into account when adjusting the parameterization coefficients for the oSP. The smallest mean difference and standard deviation result from the $m S P Z_{0}$ with $-11.57 \mathrm{~W} / \mathrm{m}^{2}$ and $24.77 \mathrm{~W} / \mathrm{m}^{2}$.

In Figure 5a the correlation between measured and parameterized fluxes is shown as a function of the sun zenith angle, in blue for the original SP, in red for the $m S P_{0}$, and in green for the $m S P Z_{0}$. In all cases the correlation is lowest with a value of around 0.7 for the smallest sun zenith angle of $\theta=30^{\circ}$, i.e for high sun conditions with large absolute values of the radiative fluxes where the cloud structure has the biggest influence on the solar radiation. The correlation increases towards $\theta=70^{\circ}$ for all three parameterizations because lower sun conditions lead to strong horizontal transports
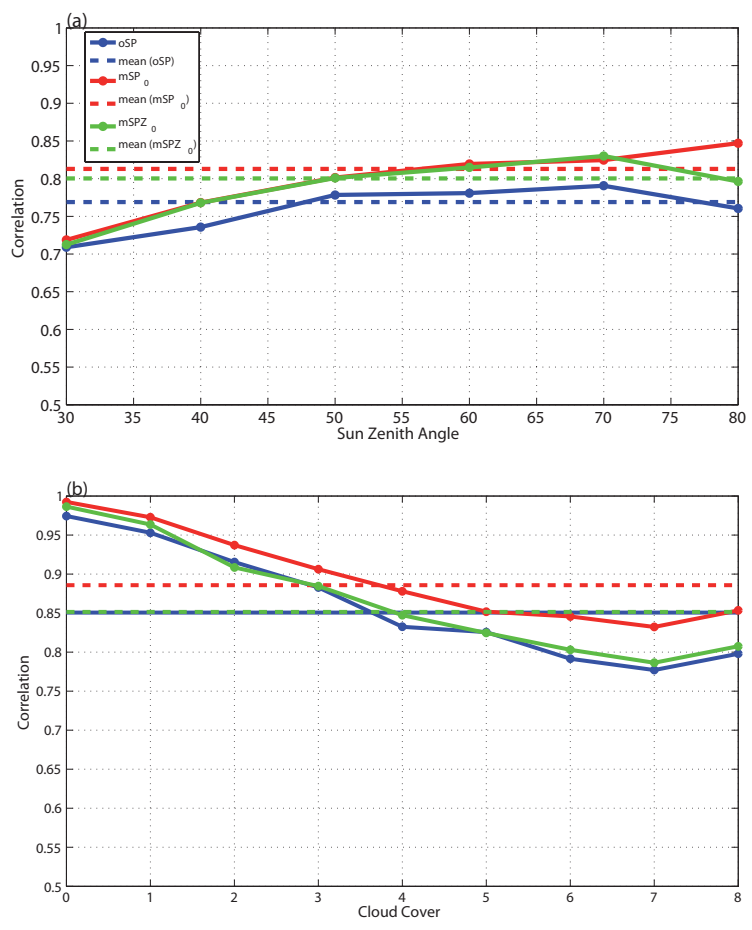

Figure 5: Correlation between measured and parameterized shortwave radiation as a function of sun zenith angle (a) and cloud cover (b)

that average out the effect of local LWP variations. In general, the modified versions show a higher correlation than the original one. For $\theta=80^{\circ}$ the correlation further increases up to 0.85 for the $m S P_{0}$ while it decreases for the other two parameterizations. On average, the $m S P_{0}$ performs best with a correlation of 0.815 , followed by the $m S P Z_{0}$ with 0.8 . The mean correlation for the original Schewski parameterization is 0.77 .

Figure $5 \mathrm{~b}$ shows the correlation between measured and parameterized shortwave radiation as a function of cloud cover. All three parameterizations show the best correlation for clear skies. In this case no cloud is influencing the radiation. The correlation for the original version is the lowest with 0.975 . After adding the Zillman parameterization the correlation increases up to 0.989 . The $m S P_{0}$ shows the best correlation with 0.993 . With increasing cloud cover up to seven octa the correlation between measured and parameterized fluxes decreases. Under broken cloud conditions the solar radiation varies on smaller timescales and the parameterizations are not able to reproduce these fluctuations. For complete overcast skies the correlation increases again for all three parameterizations because the cloud cover is nearly homogeneous. The $m S P_{0}$ shows the best correlation for all cloud cover values with an average correlation of 0.886 . The mean correlations for the other two versions are almost the same around 0.85 .

All three parameterizations are applied to an independent dataset from Lindenberg from January to Septem- 

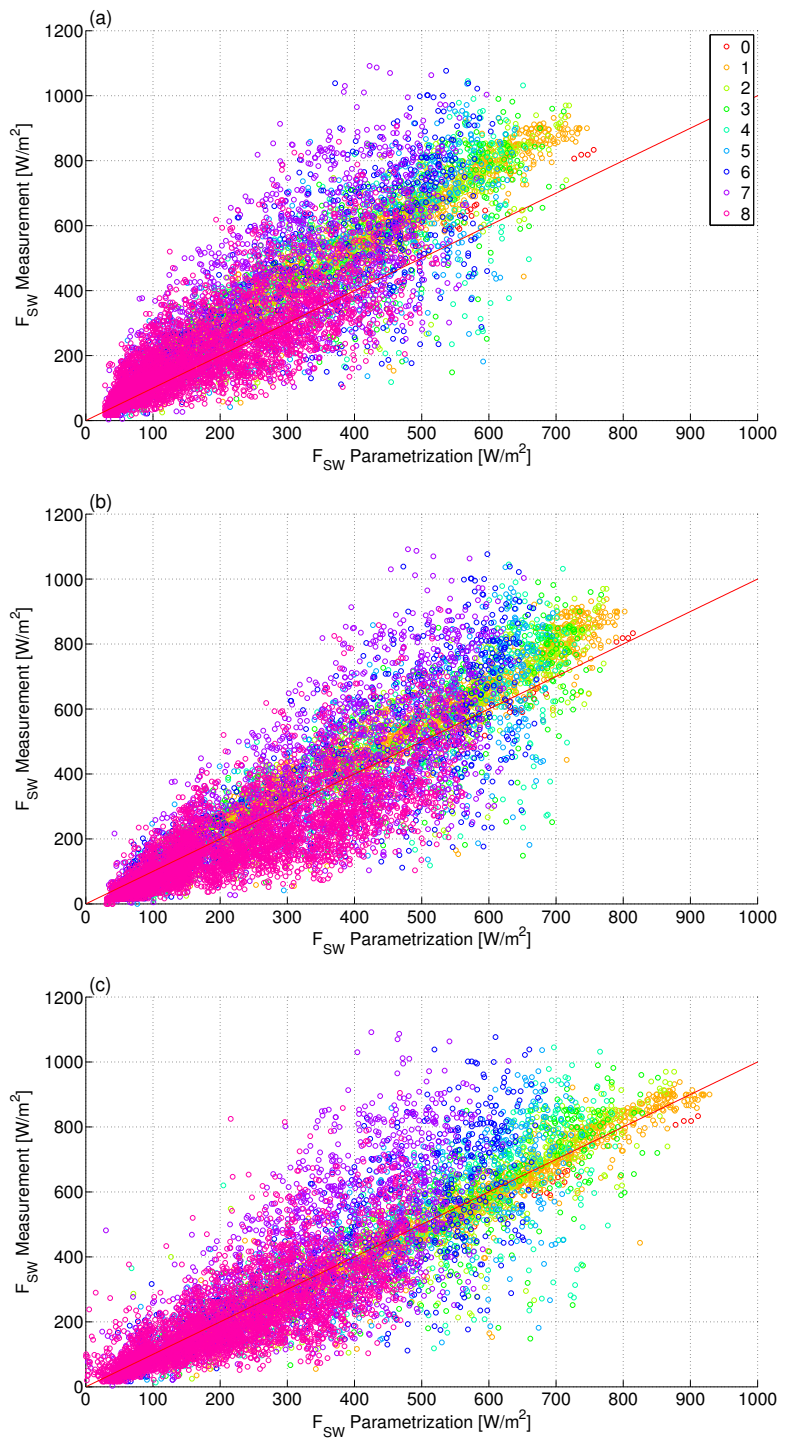

Figure 6: Comparison between measured and parameterized incoming radiation $\left[\mathrm{W} / \mathrm{m}^{2}\right]$ of the data from Lindenberg 2006 for the $o S P$ (a), the $m S P_{0}$ (b) and the $m S P Z_{0}$ (c). Different colours stand for cloud cover from 0 to 8 octa.

ber 2006. Figure 6 shows the comparison between the measured and the parameterized surface solar radiation. The original SP is shown in Figure 6a. As for the 2007 dataset it underestimates the measurements especially at large values, i.e. for clear skies or high sun conditions. The modified Schewski parameterization as shown in Figure $6 \mathrm{~b}$ yields better results. Still, it underestimates the observations at large values of the shortwave radiation. However, most points are near the one-to-one line. The $m S P Z_{0}$ shown in Figure 6c seems to reflect the high amounts of solar radiation best. The statistical analysis given in Table 5 verifies this impression. The mean value of measured minus observed fluxes is $-85.37 \mathrm{~W} / \mathrm{m}^{2}$ for the oSP. For both modified versions the mean differences are similar with $-10.49 \mathrm{~W} / \mathrm{m}^{2}$ for the $m S P_{0}$ and $-11.72 \mathrm{~W} / \mathrm{m}^{2}$ for the $m S P Z_{0}$. With
Table 5: Mean differences $(\overline{\Delta Q})$ between parameterization and measurement, the standard deviation $(\sigma)$ of the differences and the correlation (corr) between calculated and measured insolation

\begin{tabular}{|c|c|c|c|}
\hline & $\overline{\Delta Q}\left[W / m^{2}\right]$ & $\sigma\left[W / m^{2}\right]$ & corr \\
\hline \hline$o S P$ & -85.37 & 118.14 & 0.883 \\
\hline$m S P_{0}$ & -10.49 & 109.89 & 0.904 \\
\hline$m S P Z_{0}$ & -11.72 & 110.59 & 0.887 \\
\hline
\end{tabular}

$109.89 \mathrm{~W} / \mathrm{m}^{2}$ the standard deviation is slightly smaller for the $m S P_{0}$, too. For the $m S P Z_{0}$ the standard deviation is $110.59 \mathrm{~W} / \mathrm{m}^{2}$. The correlation is also best for the modified SP with 0.904, which is similar to the 2007 data set. Overall the modified Schewski parameterization shows the best results for the dataset of 2006 .

\section{Summary and conclusions}

In this work the model based Schewski-parameterization that describes the amount of the solar radiative flux as a function of sun zenith angle, cloud cover and liquid water path has been applied to cloud and radiation measurements obtained at the RAO in Lindenberg, Germany. Two modifications of this parameterization have been constructed: one that is based on the observed pairs of cloud and radiation properties $\left(m S P_{0}\right)$, and one that additionally uses a modified version of the Zillman parameterization for clear sky conditions $\left(m S P Z_{0}\right)$.

All three versions calculate the shortwave radiation as a function of domain averaged cloud cover and cloud LWP. Not surprisingly, the modified versions of the Schewski-parameterization show better results than the original one. However, the overall performance in terms of correlation coefficient and standard deviation between measured and parameterized fluxes remains similar to the original model based parameterization. It is possible to derive specific modifications that better realize sky conditions with little or with high cloudiness, but not for both. A possibility for increasing the parameterization accuracy might be the application of the variability of the parameter instead of the parameter itself. However, this approach requires much more data as currently available. We conclude that a twoparameter surface solar radiation parameterization for 10 minute means cannot be significantly improved beyond a correlation coefficient of 0.9 and a standard deviation of about $100 \mathrm{Wm}^{-2}$. In fact, NIEMELÄ et al. (2001) found smaller standard deviations in the comparison between observed and parameterized downward solar fluxes. However, their work was using hourly means whereas the present comparison is based on 10 minute averages in order to capture short term changes in the cloud fields.

In addition to cloud cover and cloud LWP their vertical structure and vertical overlap is required in large scale GCM radiative transfer schemes. The combined 
use of cloud radar and microwave radiometer enables the observation of vertical profiles of cloud liquid water and their horizontal extent (Löhnert et al., 2001). Future long term observations in this direction together with surface and satellite based radiation measurements may provide the data set for more realistic empirical radiation parameterizations.

\section{References}

Dobson, F.-W., S.-D. Smith, 1988: Bulk models of solar radiation at sea. - Quart. J. Roy. Meteor. Soc. 114, 165182.

Dupont, J.-C., M. HAEFFElin, C.-N. Long, 2008: Evaluation of cloudless-sky periods detected by shortwave and longwave algorithms using lidar measurements. - Geophys. Res. Lett. 35, L10815.

Eppel, D., M. Claussen, D. Jacob, W. Koch, L. LeVKOV, H.-T. MENGELKAMP, N. WERrmanN, E. RESCH, 1992: GESIMA - Geesthachter Simulationsmodell der Atmosphäre. - Externer Bericht 92/I/2-10, GKSSForschungszentrum Geesthacht $\mathrm{GmbH}$, Geesthacht.

Eppel, D., M. Claussen, D. Jacob, W. Koch, L. LeVKOV, H.-T. MENGELKAMP, N. WerrmanN, 1995: The non-hydrostatic mesoscale model GESIMA. Part II: Parameterizations and applications. - Contrib. Atmos. Phys. 68, 15-41.

FEISTER, U., J. SHIELDS, 2005: Cloud and radiance measurements with vis/nir daylight whole sky imager at Lindenberg (Germany). - Meteorol. Z. 14, 627-639.

Feister, U., H. MÖller, T. SAttler, J. Shields, U. GÖRSDORF, J. GÜlDNER, submitted: Comparison of macroscopic cloud data from ground-based measurements using vis/nir and ir instruments at Lindenberg, Germany. Atmos. Res.

GÜLDNER, J., J. LEPS, 2005: Analysis of CLIWA-net intensive operation period data as part of the monitoring activities at the German Meteorological Service Site Lindenberg. - Atmos. Res. 75, 151-166.

GÜldDNER, J., D. SPÄNKUCH, 2001: Remote sensing on the thermodynamic state of the atmospheric boundary layer by ground-based microwave radiometry. - J. Atmos. Oceanic Technol. 18, 925-933.

KALISCH, J., A. MACKE, 2008: Estimation of total cloud cover with high temporal resolution and parameterization of short-term fluctuations of sea surface insolation. Meteorol. Z. 17, 603-611.

KIZU, S., 1998: Systematic errors in estimation of insolation by empirical formulas. - J. Oceanography, 54, 165-177.

Levkov, L., B. Rockel, H. KAPITZKA, E. RAschKe, 1992: 3d mesoscale numerical studies of cirrus and stratus clouds by their time and space evolution. - Contrib. Atmos. Phys. 65, 35-58.

Lind, R.-J., K.-B. Katsaros, M. GubE, 1984: Radiation budget components and their parametrization in JASIN. Quart. J. Roy. Meteor. Soc. 110, 1061-1071.
LiOU, K.-N., 1980: An Introduction to Atmospheric Radiation. - Acadamic Press Inc., London.

LUMB, F.-E., 1964: The influence of clouds on hourly amounts of total solar radiation at the sea surface. - Quart. J. Roy. Meteor. Soc. 90, 43-56.

LÖHNERT, U., S. CREWELL, 2003: Accuracy of cloud liquid water path from ground-based microwave radiometry 1. dependency on cloud model statistics. - Radio. Sci. 38, 8041.

LÖHNERT, U., S. Crewell, A. MACKe, C. Simmer, 2001: Profiling cloud liquid water by combining active and passive microwave measurements with cloud model statistics. - J. Atmos. Oceanic Technol. 18, 1354-1366.

MACKe, A., D.-L. Mitchell, VON L. BREMEN, 1999: Monte carlo radiative transfer calculations for inhomogeneous mixed phase clouds. - Phys. Chem. Earth (B) 24, 237-241.

MarchuK, G., G. Mikhailov, M. Nazaraliev, R. DARbinjan, B. Kargin, B. Elepov, 1980: The Monte Carlo Methods in Atmospheric Optics - Springer Series in Optical Science, Springer Verlag, Berlin, Heidelberg, New York.

MCARTHUR, L.-J.-B., 2005: BSRN Operations Manual V2.1, WCRP 121, WMO/TD-No. 1274, April 2005. www.bsrn.awi.de/fileadmin/user_upload/Home/Publications/ McArthur.pdf

Niemelä, S., P. RÄISÄNEN, H. SAVIJÄri, 2001: Comparison of surface radiative flux parameterizations part ii. shortwave radiation. - Atmos. Res. 58, 141-154.

SCHEIRER, R., A. MACKE, 2003: Cloud inhomogeneity and broadband solar fluxes. - J. Geophys. Res. 108, 4599.

Schewski, M., A. MACKE, 2003: Correlation between domain averaged cloud properties, and solar radiative fluxes for three dimensional inhomogeneous mixed phase clouds. - Meteorol. Z. 12, 293-299.

ShiElds, J.-E., R.-W. JOHnson, M.-E. KARR, J.-L. WERTZ, 1998: Automated day/night whole sky imagers for field assessment of cloud cover distributions and radiance distributions, proc. $10^{\text {th }}$ symposium on meteorological observations and instrumentation, 11-16 January 1998. - Amer. Meteor. Soc., Boston MA.

Solheim, F., J.-R. Godwin, E.-R. Westwater, Y. Han, S.-J. KeIHM, K. MARSH, R. WARE, 1998: Radiometric profiling of temperature, water vapor and cloud liquid water using various inversion methods. - Radio Sci. 33, 393-404.

WARE, R., R. CARpenter, J. GÜldnner, J. Liljegren, T. NEHRKORN, F. SOlheim, F. VANDENBERGHE, 2003: A multichannel radiometric profiler of temperature, humidity and cloud liquid. - Radio Sci. 38, 8079, DOI:10.1029/2002S002856.

WMO, 2008: Guide to meteorological instruments and methods of observations ( 7 th ed.). - World Meteorological Organization.

ZillmAN, J., 1972: A study of Some Aspects of the Radiation and Heat Budgets of the Southern Hemisphere Oceans. - Australian Government Publishing Service, Meteorological study no. $26,562 \mathrm{pp}$. 